\title{
Análisis
}

\section{Nueva Zelanda: política comercial y patrones de comercio internacional}

Shamin Shakur*

Resumen

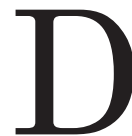
e modo general, la de Nueva Zelanda se define como una economía pequeña abierta con gran dependencia agrícola en sus ingresos por concepto de exportación. A pesar de que el comercio constituye una parte importante de su actividad económica, la vía utilizada por Nueva Zelanda no ha sido uniforme para convertirse en una nación de libre comercio. Una disminución de la tarifa promedio puede ocultar el hecho de que la estructura de las tarifas neozelandesas se mantiene tercamente dispersa. La composición del comercio neozelandés está cambiando en forma constante. Durante las décadas pasadas los productos agrícolas han dominado las exportaciones de Nueva Zelanda; sin embargo, dicha dominación decrece continuamente. Ello refleja la naturaleza dinámica de la competitividad internacional de este país. En términos

* Economía Aplicada e Internacional, Massey University, Palmerston North, Nueva Zelanda. s.shakur@massey.ac.nz de dirección de comercio, Nueva Zelanda ha desarrollado las industrias agrícola y manufacturera para satisfacer las necesidades de mercado nicho. En este artículo se brinda el soporte empírico para el modelo comercial de cambio de Nueva Zelanda y examina el entorno político, lo que conlleva a la aparición de dichos cambios.

Palabras clave: Nueva Zelanda, especialización comercial, política comercial.

\section{Introducción}

La importancia del comercio en las economías pequeñas como la de Nueva Zelanda puede difícilmente ser exagerada. Con una población de cuatro millones de habitantes, Nueva Zelanda no puede producir una amplia gama de productos para satisfacer sus propios requerimientos. El comercio con otros países les permite a las naciones utilizar en forma más productiva los relativamente abundantes recursos, y de ese modo contribuye con el aumento del nivel del ingreso real que disfruta su población. En términos de dotación de recursos, Nueva Zelanda posee más tierras económi- 
camente útiles per cápita que muchos de sus socios comerciales. Sería virtualmente imposible utilizar toda su rentabilidad en ausencia de oportunidades comerciales. En el pasado, la prosperidad de Nueva Zelanda en gran medida estuvo vinculada a su capacidad de competencia en los mercados foráneos, y ello no cambiará en el futuro. Históricamente gran parte de la exportación neozelandesa, fundamentalmente los productos agrícolas, tenían como destino al Reino Unido. Sin embargo, durante los últimos 20 años Nueva Zelanda se ha adaptado al mundo de cambios de modo que en estos momentos Asia desempeña un papel dominante. Los mercados de exportación más grandes de Nueva Zelanda son Australia, Estados Unidos y Japón. Nueva Zelanda ha desarrollado sus industrias agrícolas y manufactureras para satisfacer las necesidades de los mercados nicho. Las exportaciones de productos lácteos y cárnicos aún son de gran peso para la economía neozelandesa. No obstante, las industrias tales como la silvicultura, la horticultura, la pesca, la manufacturera y el turismo se han incrementado significativamente. En este artículo se subraya el modelo de cambio de la estructura, política y desempeño comercial externos de Nueva Zelanda durante algunas décadas y se realiza una predicción cautelosa de su camino futuro.

\section{El comercio exterior como medida de apertura}

Nueva Zelanda se afirma como una economía (relativamente) abierta. Para una isla pequeña con un mercado interno limitado, una promoción de exportaciones, en lugar de una sustitución de importaciones, se considera como un camino superior a seguir. Sin embargo, hasta 1984 la política comercial de Nueva Zelanda mostró una clara tendencia hacia la sustitución de importaciones. El sector agrícola basado en las exportaciones tenía poco de qué vanagloriarse con tal estrategia. Los ingresos por importación y los precios de las maquinarias agrícolas significaron un alto costo de producción. Un esquema detallado de los subsidios agrícolas resultó complementario de la política de sustitución de importaciones. Dicha política de distorsión de precios conllevó a una mala asignación de recursos en toda la economía. La ineficiencia y los desperdicios en el protegido sector manufacturero, la pérdida de competitividad a escala internacional en el sector agrícola, y el déficit fiscal como resultado de los subsidios, pusieron a la economía al borde de un desastre. El nuevo gobierno Laborista no tuvo en 1984 muchas opciones, aparte de encaminarse hacia una campaña de reformas drásticas, y la liberalización comercial se encontró en la vanguardia en su agenda de reformas. El comercio más libre permite la especialización, la utilización máxima de los recursos con que se cuenta, rendimientos y prosperidad; además, Nueva Zelanda no tiene motivos para regresar al régimen proteccionista que existía antes de 1984.

Nueva Zelanda es considerada una sociedad abierta tanto en términos de libertad personal como en sus relaciones comerciales externas. En su Índice de libertad económica de 2005, publicado por The Heritage Foundation, Nueva Zelanda ocupó el quinto lugar entre 161 países (véase Miles et al., 2005). El Índice constituye un reporte anual país por país sobre la apertura mundial de las economías. Entre los 10 amplios factores que determinan las clasificaciones nacionales, la libertad para comercializar con extranjeros tiene un peso significativo. Los países con mayor libertad económica poseen también tasas 


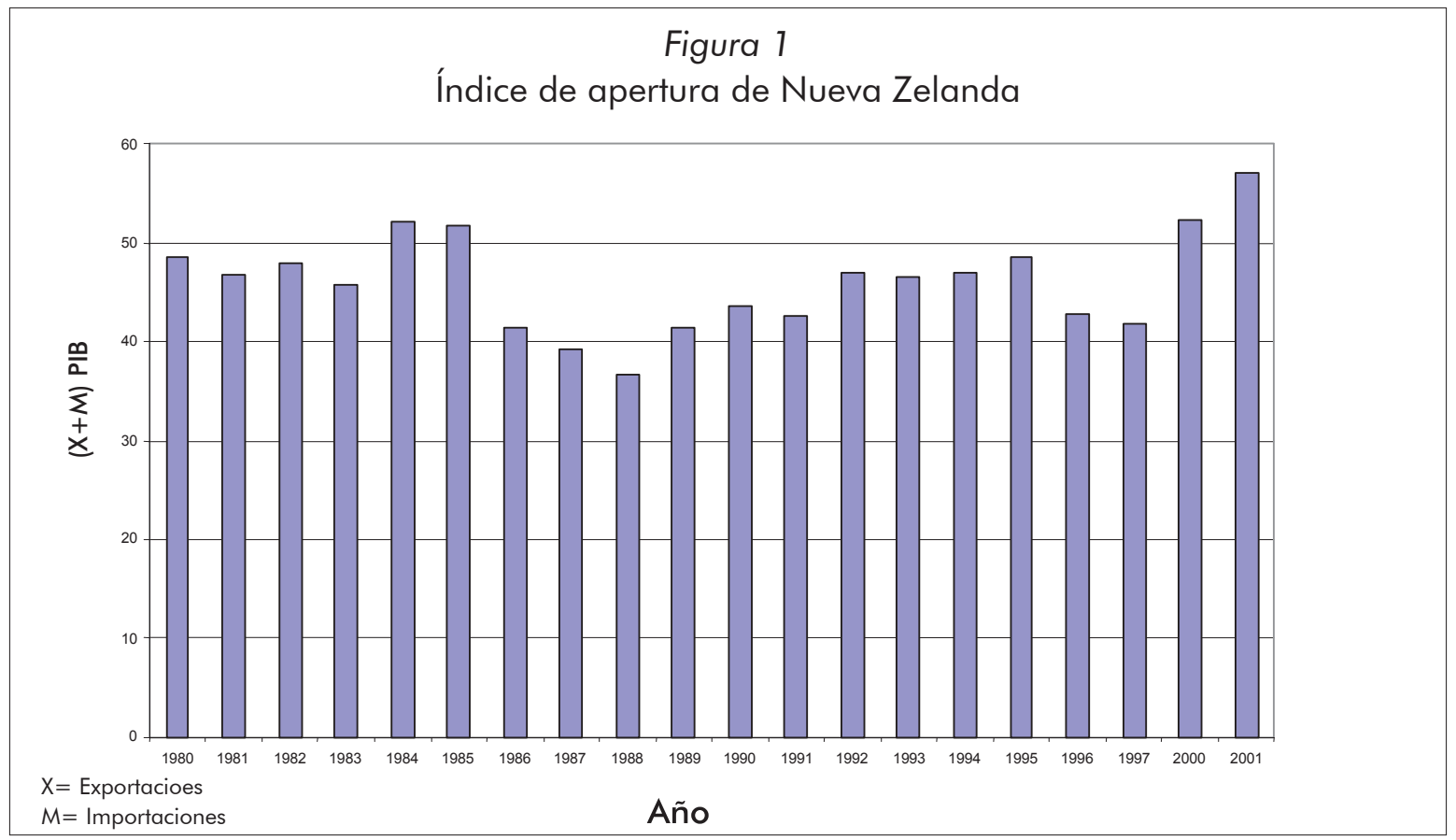

más altas de crecimiento económico a largo plazo. Debido a que el objetivo de este artículo se centra en un aspecto más estrecho del comercio, hemos utilizado la medida convencional de orientación del comercio para representar la apertura, la cual es el volumen del comercio relativo al PIB. ${ }^{1} \mathrm{Di}$ cha medida se utiliza para evaluar la vía de Nueva Zelanda como nación comercial en el transcurso del tiempo y se muestra en la figura 1.

Pueden realizarse dos observaciones en relación con la apertura de Nueva Zelanda. En primer lugar, durante la época después de la Segunda Guerra Mundial Nueva Zelanda surgió como una de las naciones comerciales más libres; sin embargo, la tendencia ha sido menos que constante. A pesar de que el comercio constituye una parte importante de la actividad económica de este país, no queda claro que la nación haya tenido una mayor apertura durante los últimos años. El comercio externo neozelandés alcanzó su máximo punto inmediatamente después de las re- formas radicales (1984-1985). Además, las reducciones de tarifas que siguieron a las reformas, la tasa de cambio flotante libre (y el levantamiento de las restricciones monetarias que viene con un dólar flexible) impulsaron el comercio exterior. Por lo general, se sabe que el volumen del comercio decae durante las épocas de recesión. Las crisis económicas en cualquier lugar, especialmente en Asia en la época actual, han tenido un impacto significativo en las relaciones comerciales neozelandesas. Históricamente, Nueva Zelanda estuvo menos abierta durante la crisis asiática de 1997-1998 (excepto en los años de recesión de 1987-1989). A partir de la crisis, y en los años más recientes, el comercio exterior de Nueva Zelanda se ha acelerado.

En segundo lugar, el uso de la definición de apertura. Al comparar el comercio exterior neozelandés con otras economías "similares", resulta que la afirmación de Nueva Zelanda como una economía abierta importante es algo exagerada. ${ }^{2}$ Muchas de las pequeñas naciones emergentes en 
Asia se considerarían más abiertas al compararse con este país. Sin embargo, en comparación con las grandes economías - los bloques comerciales en la región Asia Pacifico-, sería justo decir que Nueva Zelanda es en gran medida una economía comercial.

\section{Dirección del comercio en Nueva Zelanda}

Hasta la década de los sesenta el comercio exterior de Nueva Zelanda estuvo muy influenciado por Europa Occidental. En particular, los acuerdos comerciales preferenciales con el Reino Unido trajeron consigo que la gran mayoría de los productos agrícolas neozelandeses terminaran en un solo país. En los últimos 25 años el modelo comercial neozelandés ha cambiado significativamente. Algunos de los motivos subyacentes son obvios, mientras que otros no los son. Con la entrada de Gran Bretaña en el Mercado Común a principios de los años setenta, finalizaron los acuerdos comerciales preferenciales con las exportaciones agrícolas neozelandesas. En estos momentos el socio comercial más importante ocupa el quinto lugar desde el punto vista de Nueva Zelanda. Con el aumento de la integración económica en Europa, Nueva Zelanda fue obligada a explorar nuevos mercados. También tomó parte en la carrera para llevar a cabo los acuerdos comerciales regionales. Con la firma del Tratado de Libre Comercio entre Nueva Zelanda y Australia (NAFTA, por sus siglas en inglés, 1965), gradualmente Australia se convirtió en socio comercial importante y el acuerdo de Relaciones Económicas más Cercanas (CER, por sus siglas en inglés, que sustituyó al NAFTA en 1983) selló su estado de socio comercial más importante (Australia es el principal socio

\section{Cuadro 1}

Seis principales socios comerciales de Nueva Zelanda (1971-2003)

\begin{tabular}{lcccccc}
\hline \multicolumn{7}{c}{ Socios de exportación } \\
\hline Socio & Indicador & 1971 & 1981 & 1991 & 1999 & 2003 \\
\hline Australia & Export & 5 & 2 & 1 & 1 & 1 \\
EE.UU. & Export & 2 & 5 & 4 & 2 & 2 \\
Japón & Export & 4 & 3 & 2 & 2 & 3 \\
China & Export & 35 & 6 & 10 & 7 & 4 \\
Reino & Export & 1 & 4 & 5 & 5 & 5 \\
Unido & & & & & & \\
Korea & Export & 28 & 15 & 6 & 6 & 6 \\
\hline \multicolumn{7}{c}{ Socios de importación } \\
\hline Socio & Indicador & 1971 & 1981 & 1991 & 1999 & 2003 \\
\hline Australia & Import & 2 & 2 & 1 & 1 & 1 \\
EE.Uu. & Import & 4 & 1 & 2 & 2 & 2 \\
Japón & Import & 3 & 3 & 3 & 3 & 3 \\
China & Import & 18 & 17 & 11 & 5 & 4 \\
Alemania & Import & 6 & 8 & 6 & 6 & 5 \\
Reino & Import & 1 & 5 & 5 & 7 & 6 \\
Unido & & & & & \\
\hline
\end{tabular}

Fuente: NAPES base de datos y estadísticas de Nueva Zelanda.

comercial tanto en las importaciones como en las exportaciones; véase cuadro 1). Ello sucedió durante el periodo cuando los bajos precios de la energía y el rápido progreso en el transporte por medio de contenedores hicieron que los costos de transporte no constituyeran barreras significativas para el comercio. El aumento de la población y la duplicación del índice de crecimiento en Asia, en especial en Asía del Este, llenó muy fácil también el vacío que dejaron el Reino Unido y otras naciones de Europa Occidental. Japón se ha establecido como un importante socio comercial y las economías relativamente pequeñas como las de Hong Kong, Corea y Taiwán han surgido como socios comerciales significativos de Nueva Zelanda. El siguiente cuadro puede atestiguar estos planteamientos. En el cuadro 1 no se reportan "otros" - muchos de los cuales son de naciones en vías de desarrollo de la región asiática- - Al mismo 
tiempo, estas otras naciones se colocarían a la cabeza de los socios comerciales de Nueva Zelanda en las exportaciones e importaciones. Nueva Zelanda ha sido muy agresiva en el descubrimiento de mercados nuevos y diversificados para sus productos. Su modelo de comercio refleja los esfuerzos del país para diversificar tanto sus mercados como el alcance de sus productos. Este último aspecto, en relación con la composición comercial de Nueva Zelanda, se analiza por separado.

\section{Acuerdos comerciales}

Durante las últimas dos décadas ha habido un crecimiento fenomenal de los acuerdos comerciales bilaterales y regionales en todas las regiones del mundo. Uno de los motivos de ello es la insatisfacción con el paso de las negociaciones comerciales multilaterales bajo la omc. Nueva Zelanda se unió también a la carrera con la firma del CER en 1983. Sin embargo, muchos de los acuerdos existentes concluyeron dentro de los últimos cinco años y existen muchos más en negociaciones activas. A pesar de constituir variaciones menores en los gráficos que portan estos acuerdos, según se ejemplifica en los Acuerdos de Sociedad Económica más Cercana (CEP) las Sociedades Económicas Estratégicas (SEP) o los Tratados de Libre Comercio (FTA), en esencia todos son iguales y están diseñados para liberalizar el comercio entre las economías.

La superioridad de la liberalización del comercio multilateral respecto a la variedad bilateral queda bien establecida en la literatura (véase Shakur et al., 2002). Los posibles efectos de la desviación comercial del libre comercio regional o bilateral no estimulan los efectos de la creación del comercio a partir de éstos. En concordancia con la literatura comercial, la prioridad comercial principal de Nueva Zelanda se mantiene afianzada a los procesos de negociación multilateral, como los que realiza la oMc. Sin embargo, la escala de las negociaciones y la diversidad de intereses que se involucran, significan que el progreso por momentos puede ser lento. Por lo tanto, los acuerdos comerciales regionales y bilaterales complementan la vía multilateral en la estrategia comercial más amplia de Nueva Zelanda. Un periodo de tiempo más corto para la conclusión de estos acuerdos y un enfoque de vía rápida hacia mercados abiertos con los países que comparten el mismo nivel de ambición, son verdaderos atractivos. Nueva Zelanda permanece comprometida a los objetivos de la APEC, que consisten en el comercio e inversión libre y abierta dentro de la región Asia-Pacífico para el año 2010; sin embargo, siente que la otra necesidad de iniciativas regionales no esperará mucho. A continuación se muestra una lista con las iniciativas comerciales regionales de Nueva Zelanda en diferentes estados de operación:

\section{Acuerdos comerciales en vigor}

- Sociedad Económica más Cercana, Nueva Zelanda y Tailandia (NZTCEP) $-2005$.

- Sociedad Económica más Cercana, Nueva Zelanda y Singapur (NZTCEP) - 2001.

- Relaciones Económicas más Cercanas, Australia y Nueva Zelanda (CER) - 1983.

Acuerdos comerciales terminados pero aún no puestos en vigor

- Sociedad Económica Estratégica TransPacific (Trans-Pacific SEP) - 2005. 
- Brunei/Chile/Nueva Zelanda/Singapur.

\section{Acuerdos en negociación}

- Tratado de Libre Comercio Nueva Zelanda y China.

- Tratado de Libre Comercio ASEAn-Australia/Nueva Zelanda.

- Tratado de Libre Comercio Nueva Zelanda y Malasia.

- Sociedad Económica más Cercana, Nueva Zelanda-Hong Kong.

\section{Composición del comercio neozelandés}

En comparación con sus socios comerciales principales, Nueva Zelanda es un país con relativamente muchas tierras. Otros factores naturales como las altas precipitaciones y las temperaturas moderadas durante todo el año proporcionan condiciones muy favorables para un próspero sector agrícola. Por consiguiente, los productos agrícolas han sido los principales rubros exportables para Nueva Zelanda. Ello a pesar de que la contribución del sector agrícola ha sido pequeña en términos de la actividad económica agregada (según la medida del PIB). Popularmente, Nueva Zelanda es considerada una nación agrícola debido a su predominio del comercio.

La composición del comercio neozelandés cambia constantemente. Esto refleja la naturaleza dinámica de su competitividad internacional. Durante los últimos 30 años las exportaciones agrícolas ha predominado; sin embargo, este predominio ha ido decayendo de forma continua. La tendencia es contraria a lo que ha estado ocurriendo con las exportaciones manufactureras y mineras - un incremento a partir de niveles insignificantes a cifras apreciables.

\section{Especialización}

La teoría comercial plantea la obtención de ganancias a partir del incremento comercial de dos fuentes: la especialización y el

Figura 2

Composición de las exportaciones neozelandesas 1964-2004

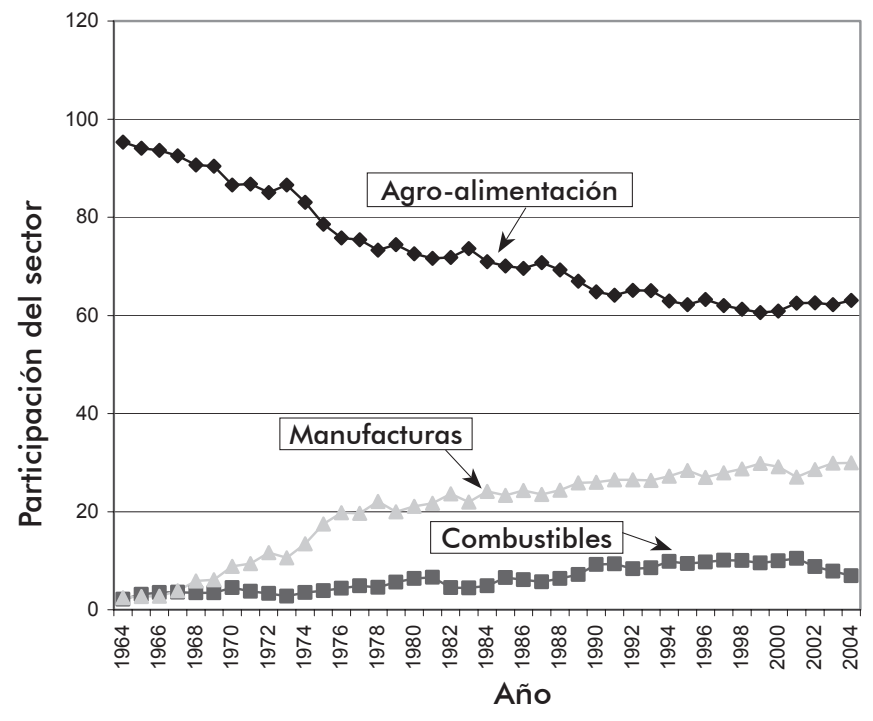




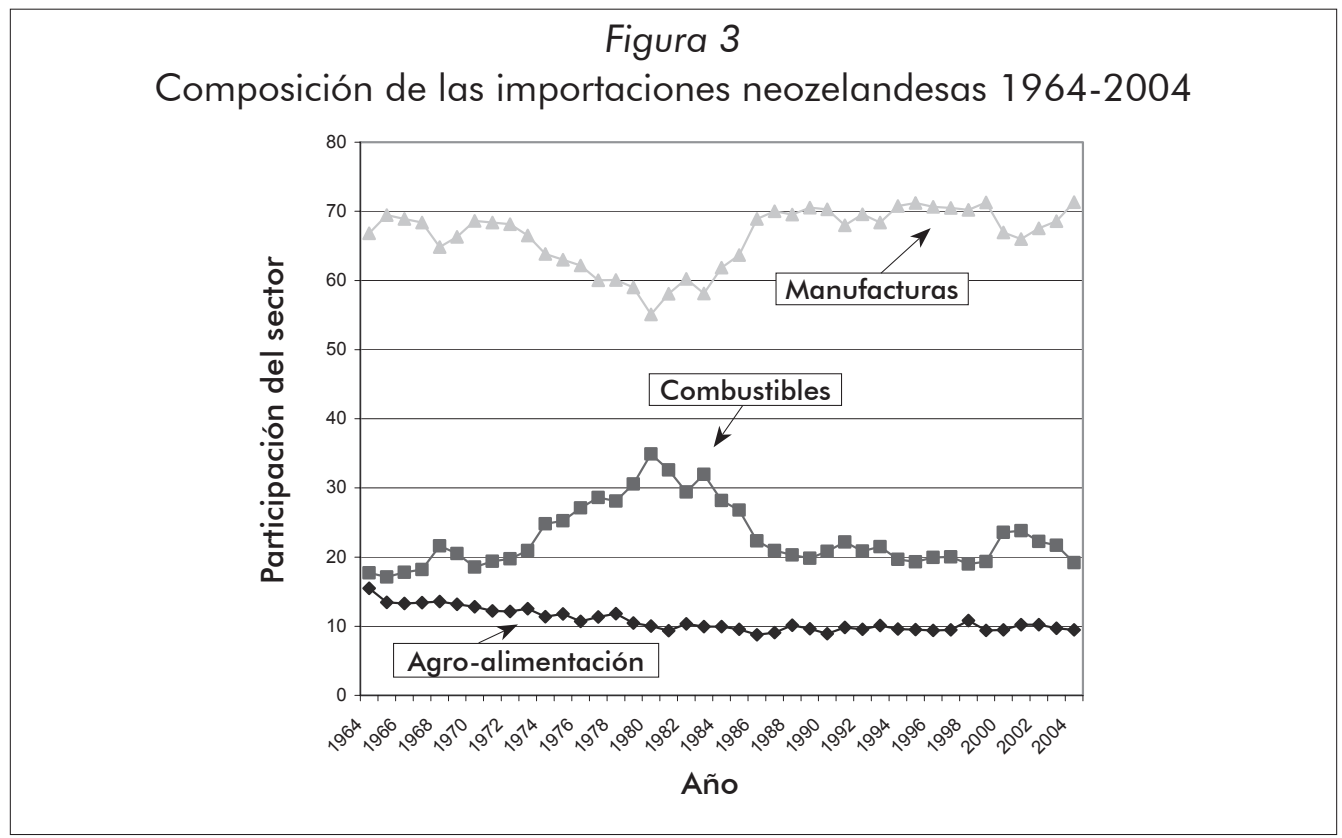

intercambio. El índice de especialización comercial se define como la exportación neta de cada sector en relación con la suma de exportaciones e importaciones sectoriales. O sea:

$$
\operatorname{ITS}_{\mathrm{i}}=\left(\mathrm{X}_{\mathrm{i}}-\mathrm{M}_{\mathrm{i}}\right) /\left(\mathrm{X}_{\mathrm{i}}+\mathrm{M}_{\mathrm{i}}\right)
$$

Por lo tanto, el indicador puede producir un valor entre $-1 \mathrm{y}+1$. Esas cifras se calculan durante 40 años, terminando en 2004 y se muestran en la figura 4. Este indicador no muestra una tendencia diferente para el sector agrícola. La observación es similar para el caso de Australia, donde el índice se ha mantenido de forma persistente en alrededor de $+2 / 3$ prácticamente sin tendencia desde 1950 hasta principios de 1990 (Pomfret, 1995: 35). En comparación con Australia, el comercio neto de Nueva Zelanda permanece más especializado en la agricultura. Para otros sectores, principalmente los combustibles y minerales y manufacturas, este indicador es altamente negativo pero en decadencia. Ello indica que Nueva Zelanda gana ventaja competi- tiva en sus sectores no tradicionales. Dicha diversificación va en contra del principio de ventaja comparativa; no obstante, se considera saludable desde el punto de vista de ventaja competitiva.

\section{Desempeño del comercio neozelandés}

La medida de rendimiento más importante en el comercio con el resto del mundo son los términos de intercambio, que se definen como el precio relativo de las exportaciones sobre las importaciones. Nueva Zelanda disfrutó de excelentes términos de comercio en los años sesenta. Los precios preferenciales para sus exportaciones agrícolas a Gran Bretaña dan crédito a esta afirmación. No obstante, los precios de las materias primas han experimentado un deterioro secular en términos comerciales durante mucho tiempo, y Nueva Zelanda no escapa a esta realidad. Los peores niveles se observaron cerca de los periodos de liberalización (19821986) y de la crisis asiática (1997-2000); sin embargo, en los últimos años este indicador

14 MÉXICO YLACUENCADELPACÍFICO 
Figura 4

Índice de especialización del comercio de Nueva Zelanda

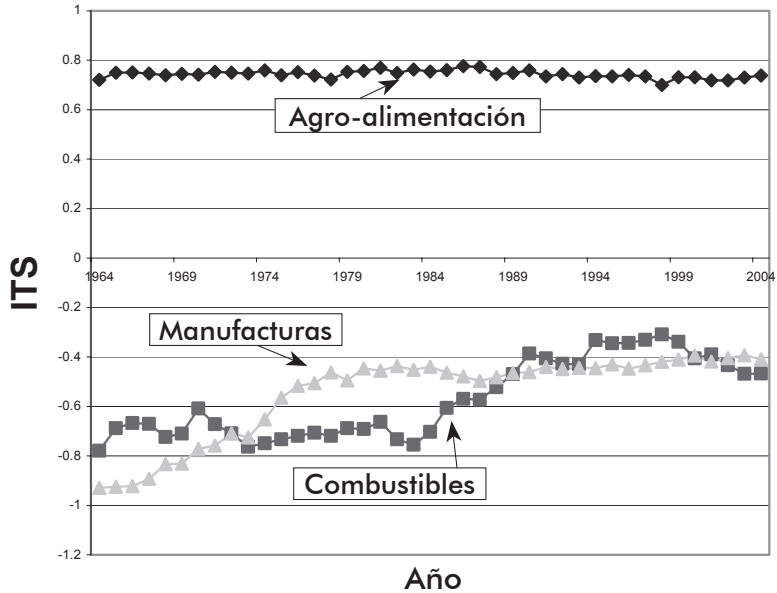

ha mejorado notablemente, según se puede observar en la figura 5. Los términos de intercambio más recientes de Nueva Zelanda muestran que se está beneficiando del actual auge del mercado mundial. Con el vertiginoso aumento de los precios del crudo en 2005, y la dependencia de Nueva Zelanda del petróleo importado, esta tendencia probablemente cambiará más bien rápidamente.

Otra medida un tanto popular del desempeño comercial es el equilibrio de cuenta corriente. Un exceso en el equilibrio de cuenta corriente se considera bueno, ya que incrementa las demandas respecto al resto del mundo. Por otro lado, un déficit en el equilibrio de cuenta corriente puede ser malo, ya que aumenta las demandas extranjeras en contra de la economía interna. Por esta razón, el desempeño comercial neozelandés ha sido ensombrecido y no muestra señales de mejoría. Según puede observarse en la figura 6 , durante los últimos 40 años Nueva Zelanda nunca disfrutó

Figura 5

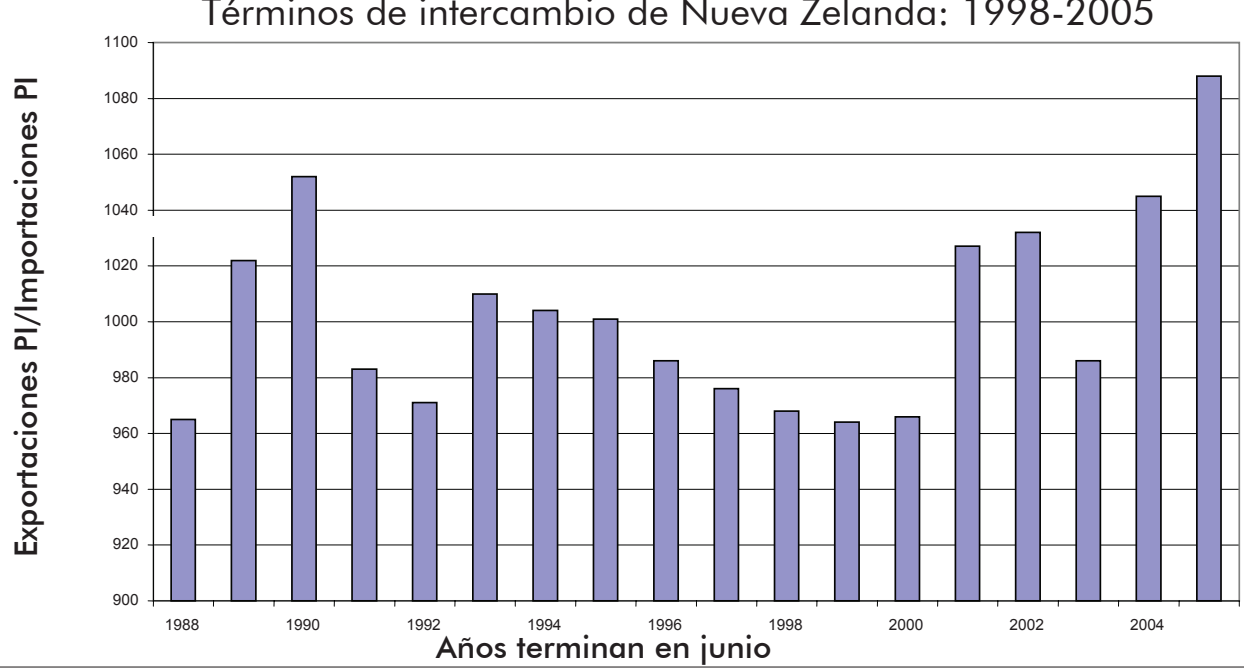


de un año con exceso de cuenta corriente. El déficit sobrepasó 13 por ciento del PIB en dos ocasiones -durante el auge de la crisis energética en 1975 y en 1984-1985, cuando Nueva Zelanda fue obligada a realizar las drásticas reformas-. Muchos economistas creen que un déficit de cuenta corriente por encima de 7 por ciento del PIB es insostenible. Desafortunadamente, en 1975 el déficit de cuenta corriente se aproximó al umbral y, con los precios del crudo sin precedentes, este déficit probablemente empeore. El extenso y persistente déficit de cuenta corriente en los países afectados fue considerado como el motor impulsor de la crisis asiática de 1987-1998. Shakur (2002) comparó la situación de Nueva Zelanda con los países más afectados, Indonesia y Tailandia, y descubrió que el déficit de cuenta corriente de Nueva Zelanda fue el peor.

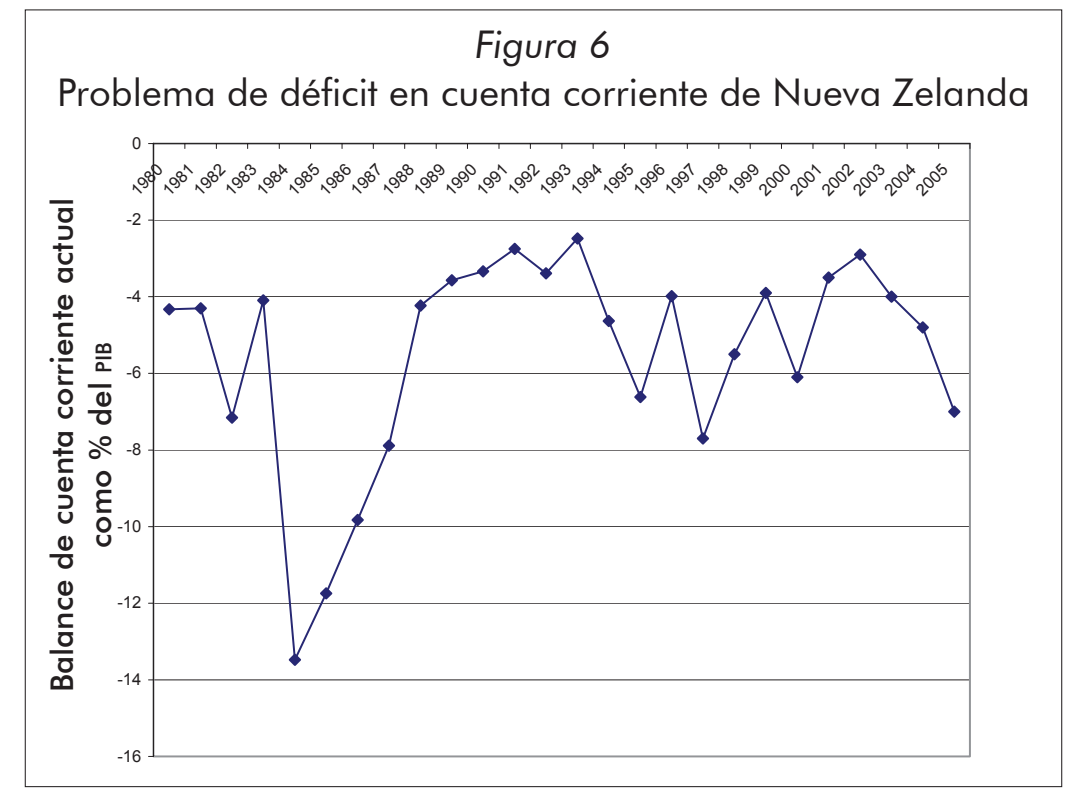

\section{Estructura y política de las tarifas neozelandesas}

Desde que comenzó el proceso de reforma en 1984, Nueva Zelanda ha reducido sus tarifas constantemente. A mediados de los noventa el gobierno del partido nacional trazó una política para sustituir unilateralmente todas las tarifas para el año 2006. Sin embargo, en abril de 2000, en un abrupto giro en $U$ de esta política, el gobierno Laborista acordó detener el proceso de reducción de tarifas mediante la congelación de éstas a los niveles de julio de 1999 hasta julio de 2005. Por ahora, el gobierno está revisando las opciones de políticas de tarifas para después del año 2005.
A pesar de este cambio de política, los niveles de Nueva Zelanda en estos momentos son bajos, según el estándar mundial, con un simple promedio de tasa arancelaria de Nación Más Favorecida (MFN, por sus siglas en inglés) de 3 por ciento. ${ }^{3}$ En 2002 los impuestos recaudados en todas las importaciones totalizaron $\$ 288$ millones (-0.7 por ciento del ingreso del gobierno). En la actualidad, alrededor de 95 por ciento de las importaciones neozelandesas, por valor, se admiten libre de impuestos. Para los artículos que aún están sujetos a impuestos, la tarifa es generalmente baja (de entre 5 y 7 por ciento). Dada la gran proporción de importaciones que están lo mismo fuera de impuesto por medio de concesiones de 
Figura 6

Países con problemas de cuenta corriente durante la crisis asiática

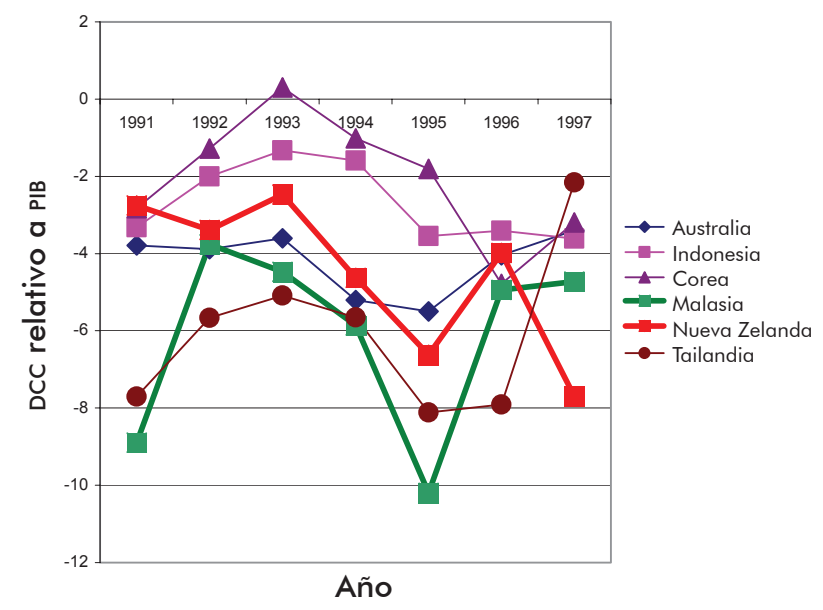

tarifas o sujetas a preferencias de tarifas, la tasa arancelaria media a través de todos los productos manufacturados es apenas de 1 por ciento. Una estructura de tarifa uniforme y baja es un elemento importante de un régimen de tarifa sin distorsiones. Sin embargo, Nueva Zelanda mantiene altas tasas arancelarias para una gama seleccionada de productos. Por ejemplo, las industrias textil, de confección y del calzado (TCC) atraen tarifas de hasta un 19 por ciento y los componentes de automóviles poseen tasas tan altas como de un 11.5 por ciento. Desde 1984 Nueva Zelanda se ha alejado de las restricciones cuantitativas en la administración de su política comercial. El sector avícola, que disfruta de protección total de importaciones, es una excepción ya que las importaciones de productos avícolas no están permitidas por razones fitosanitarias. En términos del Estimador del Apoyo al Productor (PSE), los agricultores neozelandeses recibieron alrededor del 2 por ciento de beneficio, lo que los ubica al final del cuadro de la OCDE. Para el sector avícola, el PSE se mantiene alto (55.3 por ciento para las carnes de aves de corral, 22.2 por ciento para los huevos).
Ningún otro sector registró más de 3 por ciento del PSE desde 1990. Una vez más, ello significa una relativamente alta dispersión alrededor de un promedio muy bajo.

La liberalización comercial que involucra los sectores seleccionados es muy popular en muchos países. Los ejemplos incluyen la liberalización sectorial voluntaria y temprana de la APEC y los acuerdos cero por cero. Desde el punto de vista de la eficiencia económica, dichos esquemas pueden crear nuevas distorsiones y pueden ser dañinos para la asistencia social. La utilización del modelo de equilibrio general aplicado (Rae, Chatterjee y Shakur, 2001) calculó las pérdidas asociadas con dichos esquemas de liberalización comercial selectiva para cierto número de países. En cambio, los beneficios de una reducción generalizada en las tarifas fueron abrumadores.

El Banco Mundial ubica a los países individuales según las tasas arancelarias promedio aplicadas sobre las importaciones como parte de la medida global de apertura y competitividad internacional. Las tarifas promedio, según sus cálculos, son el promedio simple de las tasas aplicadas para todos los productos sujetos a 
tarifas. Antes de su moratoria sobre posteriores reducciones de tarifas en el año 2000, Nueva Zelanda se ubicó en el séptimo lugar, con una tarifa de 4.5 por ciento por encima de Australia y de Estados Unidos. ${ }^{4}$ En efecto, si se obvian las ciudades Estados de Hong Kong y Singapur, Nueva Zelanda se ubicaría por encima de todos los países del Asia Pacífico. Esto es muy admirable. La desviación estándar de las tasas arancelarias mide la desviación promedio de las tasas arancelarias alrededor del promedio; se calcula utilizando los datos de las tarifas sin considerar su peso relativo. Las tasas altamente dispersas constituyen una prueba de las tarifas discriminatorias, que no prometen la competitividad internacional. En el caso de Nueva Zelanda, la desviación estándar de 6 por ciento fue mejor que la de la mayoría de sus socios comerciales, pero se queda un poco corta en relación con los países de la Unión Europea.

\section{Conclusión}

La globalización ha sido parte integral de la economía neozelandesa. La prosperidad de Nueva Zelanda está directamente vinculada con su capacidad de encontrar mercados nicho para nuestros productos con valor agregado y asegurar mejores precios de exportación para sus artículos de primer orden. La intensidad del comercio neozelandés se ha frenado en los últimos años. Un persistente y prácticamente insostenible déficit en la cuenta corriente contribuye a la lentitud del proceso de liberalización comercial. A pesar de que la revisión de las políticas se justifica en tiempos excepcionales, el proteccionismo y las políticas encerradas en sí mismas no pueden ser una opción viable para Nueva Zelanda. La incapacidad o la falta de voluntad para abrir el comercio significarán la subutilización de sus abundantes recursos naturales y el empobrecimiento. Esto se aplica al resto del mundo tanto como a Nueva Zelanda. Desde la Segunda Guerra Mundial el comercio ha sido el motor del crecimiento en todo el mundo; sin embargo, las fuerzas proteccionistas aún están vivas. Nueva Zelanda hace la gran apuesta en la exitosa conclusión de la Ronda de Doha, ya que promete una postericniviliberalización comercial a escala global.

\section{Notas}

1 Véase Pomfret (1995), p. 41-43.

2 El índice de apertura de Nueva Zelanda se compara con sus principales socios comerciales y regionales.

3 La tasa de promedio simple de la tarifa se obtiene al promediar la tasa de tarifa del MFN de todos los artículos de tarifa, incluidos los artículos de tarifas libres de impuestos. Cada artículo sujeto a tarifa porta el mismo peso, a pesar de las variaciones significativas del valor de las importaciones que porte cada artículo de tarifa.

4 En 2002, año más reciente del que se dispone de los datos del Banco Mundial, la tasa de tarifa promedio de Nueva Zelanda fue reportada en 2.8 por ciento.

\section{Bibliografía}

Miles, M. A, E. J. Feulner, y M. A. O'Grady (2005) 2005 Index of Economic Freedom: The Link between Economic Opportunity and Prosperity. Washington, DC: The Heritage Foundation.

Pomfret, Richard (ed.) (1995) Australia's Trade Policies. Oxford: Oxford University Press.

Rae, A. N., S. Chatterjee, y S. Shakur (2001) "The Sectoral Approach to Trade Liberalization: Should We Try to do better?", International Trade Journal, vol. 15, núm. 3, pp. 293-322.

Shakur, S. (2002) New Zealand's Changing Trade Pattern and Policies, New Zealand Agricultural and Resource Economics Society Conference, Blenheim, Nueva Zelanda.

Shakur, S., A. N. Rae, y S. Chatterjee (2002) "How Comprehensive will be the Doha Round?", Proceedings of the Eighth International Convention of the East Asian Economic Association, Kuala Lumpur, Malasia. 